IZA DP No. 4194

How Large is the Compensating Wage Differential for R\&D Workers?

Arnaud Dupuy

Wendy Smits

May 2009 


\title{
How Large Is the Compensating Wage Differential for R\&D Workers?
}

\author{
Arnaud Dupuy \\ ROA, Maastricht University \\ and IZA \\ Wendy Smits \\ Statistics Netherlands and ROA
}
Discussion Paper No. 4194
May 2009

IZA
P.O. Box 7240
53072 Bonn
Germany

Phone: +49-228-3894-0

Fax: +49-228-3894-180

E-mail: iza@iza.org

\begin{abstract}
Any opinions expressed here are those of the author(s) and not those of IZA. Research published in this series may include views on policy, but the institute itself takes no institutional policy positions.

The Institute for the Study of Labor (IZA) in Bonn is a local and virtual international research center and a place of communication between science, politics and business. IZA is an independent nonprofit organization supported by Deutsche Post Foundation. The center is associated with the University of Bonn and offers a stimulating research environment through its international network, workshops and conferences, data service, project support, research visits and doctoral program. IZA engages in (i) original and internationally competitive research in all fields of labor economics, (ii) development of policy concepts, and (iii) dissemination of research results and concepts to the interested public.
\end{abstract}

IZA Discussion Papers often represent preliminary work and are circulated to encourage discussion. Citation of such a paper should account for its provisional character. A revised version may be available directly from the author. 
IZA Discussion Paper No. 4194

May 2009

\begin{abstract}
How Large Is the Compensating Wage Differential for R\&D Workers?

The aim of this paper is to measure the extent to which lower wages in R\&D functions reflect a preference effect. In contrast to the bulk of the literature on compensating wage differentials that compares wage levels of jobs with different attributes, we constructed measures of willingness to accept (WTA) and pay (WTP) for an R\&D jobs using contingent valuation technique. Earnings regressions using OLS show an R\&D wage penalty of about 3.5\%. However, hedonic OLS regressions of WTA and WTP give significant relative preference parameters for $R \& D$ jobs that range from 0.19 to 0.22 .
\end{abstract}

JEL Classification: J3

Keywords: $\quad$ R\&D workers, compensating wage differentials, hedonic prices

Corresponding author:

Arnaud Dupuy

Maastricht University

P.O. Box 616

NL-6200 MD Maastricht

The Netherlands

E-mail: a.dupuy@roa.unimaas.nl

\footnotetext{
* We thank two anonymous referees for their helpful comments. The comments of participants at the 'The labour Market for Scientists and Engineers' workshop at Maastricht University and participants of the CPB seminar are also gratefully acknowledged.
} 


\section{Introduction}

Although it has long been recognized that agreeable and disagreeable job characteristics should be reflected in wages, empirical evidence on this issue is scarce and concentrates mainly on compensation for risks, stress, noise and bad working conditions. Recently, several papers have started documenting compensations for specific types of jobs. Krueger and Schkade (2007) concentrate on the compensations for social interaction on the job and Stern (2004) on compensation for doing scientific research.

In this paper we consider the preferences of scientists and engineers for R\&D functions. Scientists and engineers working in R\&D functions in general earn less than scientists and engineers working in other technical and management occupations (e.g. Lassibille, 2001). Shortages of R\&D workers are often attributed to low wages in R\&D functions (e.g. Marey, 2002) but if these low wages reflects preferences, wage policies will not be very efficient in increasing the number of $R \& D$ workers. The aim of this paper is to measure the extent to which lower wages in $R \& D$ functions reflect a preference effect.

In most of the literature compensating wage differentials (CWDs) are estimated by comparing wage levels of jobs with different attributes. The main problem with this approach is that more able workers, or workers with higher earnings capacity in general, command jobs with more agreeable nonfinancial attributes. The omitted variable bias created by unobserved heterogeneity, therefore, leads to underestimation of CWDs (e.g. Brown, 1980). In attempts to account for this problem, studies in the related literature (see Lassibille (2001) for instance) have used instrumental variable techniques or self-selection methods like Heckman's two step procedure or switching regression models. However, as Epple (1987) and Kahn and Lang (1988) already argued, because in equilibrium workers characteristics (observed and unobserved) are mapped onto jobs characteristics (observed and unobserved), there exist no valid (external) instruments or exclusion restrictions for either sets of characteristics, at least in a single cross-section. This means that, in a single cross-section, IV methods cannot be used to estimate consistently workers and/or firms preference parameters from data on wages. Similarly, identification in self-selection models will rely merely on the nonlinearity of hazard rates since exclusion restrictions are ruled out by the mapping of workers characteristics on jobs characteristics.

In this paper, we circumvent this problem of eliciting preferences from wage data by eliciting workers' willingness to accept (WTA) and pay (WTP) for an R\&D job directly from survey questions. Workers' WTA/P are measured through Contingent Valuation method conducted in a survey among Dutch scientists and engineers containing information, among other, on work- 
ers' wages and job types. The Contingent Valuation method gives us a direct measure of a person's preference for R\&D jobs which allows us to directly estimate R\&D preference parameters by regressing workers' WTA and WTP on workers' characteristics.

Earnings regressions using OLS show a wage penalty for R\&D workers of $3.5 \%$. However, our measures of WTA indicates that the willingness of scientists and engineers working in R\&D functions to accept a job in a non$\mathrm{R} \& \mathrm{D}$ function is $15 \%$ of their current wage, in contrast to scientists and engineers working in non- $\mathrm{R} \& \mathrm{D}$ functions whose willingness to accept an R\&D function is $7 \%$ of their current wage. Similarly, our measure of WTP indicates that the willingness of scientists and engineers working in $R \& D$ functions to pay in order to hold an R\&D function is $11 \%$ of their wage which contrasts with the willingness of scientists and engineers working in non-R \&D functions to pay for a non-R \&D function of $8 \%$. Using OLS we find significant estimates of the preference parameter towards $R \& D$ jobs relative to non-R \&D jobs. Our estimate points range between $0.19 \log$ points and $0.22 \log$ points.

This paper is related to Stern (2004). Stern (2004) circumvented the sorting issue in the context of R\&D compensation by comparing multiple job offers for $\mathrm{PhD}$ biologists. He found large compensating wage differentials for science orientated jobs, i.e. scientist are prepared to accept a wage reduction of $19 \%$ for a job in which they can freely publish their research results in external journals. Note that while we are concerned by the extensive margin of the problem, that is the question of whether to choose an R\&D job or not, Stern's (2004) results refer to the intensive margin by looking at the compensation required to being able to freely publish conditional on have chosen an R\&D job. While Stern's approach provides consistent estimates of the CWD and has the advantage to be based on real transactions as opposed to our approach that is based on answers to hypothetical questions, Stern's data are rare and extremely costly to produce whereas our method could be implemented in any survey at very low costs.

\section{Methodology}

Suppose that the utility of a worker with characteristics $x$ is $u_{R D}\left(w_{R D}, x\right)$ if she works in an R\&D job and $u_{N R D}\left(w_{N R D}, x\right)$ otherwise where:

$$
u_{j}\left(w_{j}, x\right)=h_{j}\left(w_{j}\right)-f_{j}(x)
$$


$w_{j}$ is the worker's wag $\oint^{1}$ at job $j$ and $f_{j}(x)$ her disutility of working at job $j$. Assuming that $h_{j}\left(w_{j}\right)=\ln w_{j}$ the worker is indifferent between R\&D and non-R\&D jobs if:

$$
\begin{aligned}
u_{N R D}\left(w_{N R D}, x\right) & =u_{R D}\left(w_{R D}, x\right) \\
& \Leftrightarrow \\
\ln w_{N R D}-\ln w_{R D} & =f_{R D}(x)-f_{N R D}(x)
\end{aligned}
$$

The left hand side of the equation corresponds to worker's CWD for not working in an $\mathrm{R} \& \mathrm{D}$ job. If $C W D>0$, the worker has a preference for $R \& D$ relative to non- $R \& D$ jobs. Without information on the CWD it is not straightforward to estimate the preference function $f_{R D}(x)-f_{N R D}(x)$. In general we will observe either $w_{R D}$ or $w_{N R D}$ of each worker. The coefficient of an R\&D dummy in an OLS regression of (log) wages will not identify the preference parameters because in equilibrium workers characteristics will be mapped onto job characteristics, at least in a single cross section. To see this consider an economy with two types of jobs, R\&D and non-R \&D. This economy has 10 workers who differ in terms of a vector of characteristics $x$. These characteristics are determinants of a worker's preference towards R\&D jobs. Suppose that, for each worker, the minimum wage difference between non-R\&D and R\&D jobs, for which she would be willing to work in an R\&D job is known and given by $C W D=C W D(x)$. The higher the CWD, the higher the preference for R\&D jobs. We could rank workers by decreasing $C W D$ (decreasing preference for $\mathrm{R} \& \mathrm{D}$ jobs) and plot $C W D$ on the rank (see Table 1). Assuming full employment, that is assuming that $C W D$ is larger than the reservation wage for each worker, the equilibrium wage premium given the demand for R\&D workers could be directly inferred by inspection of this graph. If there were $N \mathrm{R} \& \mathrm{D}$ jobs in the economy, the wage premium necessary to induce the $N^{t h}$ worker to work in an R\&D job is $-C W D$ of the worker ranked $N^{\text {th }}$.

As a consequence, unless workers are homogenous in terms of their preference towards R\&D jobs, i.e. $C W D(x)=C W D\left(x^{\prime}\right)$ for all $x$ and $x^{\prime}$, the mean wage of $R \& D$ workers relative to the mean wage of non- $R \& D$ workers conditional on $x$-to control for the direct effect $x$ might have on wageswill depend on the demand for R\&D workers. To see this, suppose that there are $4 \mathrm{R} \& \mathrm{D}$ jobs in the economy. The OLS estimate of the R\&D dummy will be -2.2 , i.e. minus the $C W D$ of the fourth worker. Consider now the same

\footnotetext{
${ }^{1}$ The wage could depend on $x$ as well as on additional characteristics $y$ that are unrelated to preferences for $\mathrm{R} \& \mathrm{D}$ and written as $w_{j}(x, y)$ without changing the main structure of the model.
} 
economy but with $8 \mathrm{R} \& \mathrm{D}$ jobs. The OLS estimate of the R\&D dummy is equal to 4.2 , which is equal to minus the $C W D$ of the ninth worker. In the first case we would conclude that there is a relative preference for $R \& D$ jobs, in the second case that there is a relative preference for non-R\&D while the structure of preferences is clearly the same in both cases.

This simple example illustrates the idea that the coefficient of an R\&D dummy in an OLS regression of (log) wages on workers and firms characteristics will not identify preference parameters and hence will not allow one to trace out the function $C W D(x)$ unless all characteristics that matter in determining a worker's $C W D$ are observed. This is a very strong assumption that is most unlikely to be met in any dataset. The sign of the bias will tend to be negative as those that select into $\mathrm{R} \& \mathrm{D}$ occupations tend to have characteristics that lowers their WTA and therefore will command a lower compensation.

Confronted with an omitted variable problem, the econometrician might screen the data for a valid instrument for $\mathrm{RD}$ and use instrumental variable techniques or control function models of the Heckman type or switching regression models to estimate the coefficient of the R\&D-dummy consistently. However, the problem at hand, unlike the traditional omitted variable bias problem, is more severe. Usual instruments for R\&D from the other side of the market, i.e. variables containing information about employers or jobs in our case, are ruled out by the mapping of workers characteristics onto jobs characteristics in equilibrium, at least in a single cross-section ${ }^{2}$ Even if workers do not care about certain characteristics of their employers, these employers characteristics are likely to be determinants of whether an employer offers an R\&D job or not. The equilibrium mapping therefore rules out the use of IV methods in single cross-section and that identification in the selection models hinges on the nonlinearity of the control function. For that reason we tried to obtain direct measures of the worker's CWD for an R\&D Job. These measures can be used to estimate directly equation 1. Note that this equation corresponds to the well-known second stage of Rosen's procedure to estimate the preference parameters when job characteristics are continuous variables(see Rosen (1974)). Assuming that i) $f_{j}(x)$ is additive separable in the observed and unobserved characteristics $x$, i.e.

\footnotetext{
${ }^{2}$ In footnote 5 page 119, refering to this problem, Brown (1980) stated that:

[...finding instruments for $Z$ (read RD in our case) that are not themselves $X$ 's $(\operatorname{read} x)$ would be extremely difficult]
}

In fact, as pointed out earlier in the hedonic price literature by Bartik (1987b), Epple (1987) and Kahn and Lang (1988), it is impossible if workers characteristics are mapped on employers characteristics 
$f_{j}(x)=g_{j}\left(x^{o}\right)+h_{j}\left(x^{u}\right)$ and proxying $g_{j}$ by polynomial form of order 2, i.e. $g_{j}(x)=\alpha_{j}+X \beta_{j}$, ii) $h_{j}\left(x^{u}\right)$ is multivariate normal with a covariance matrix that accounts for the cross alternative dependence and allows unobserved heterogeneity across individuals and iii) $h_{j}\left(x^{u}\right)$ is uncorrelated with $g_{j}\left(x^{o}\right)$ we estimate:

$$
C W D=\alpha+\gamma R D+X \beta+e
$$

where $e=h_{R D}\left(x^{u}\right)-h_{N R D}\left(x^{u}\right)$ and $X$ stands for a vector of variables that are transformations of $x^{o}$, i.e. squared $x$ or interaction across $x^{o}$ 's.

Note that the inclusion of the $R \& D$ dummy in this regression only aims at picking up unobserved preference differences between $R \& D$ workers and non $R \& D$ workers. Ideally, we would have a rich enough set of variables in our data to explain preferences so that our estimate of $\gamma$ will tend to 0 . If not, $\gamma$ will give us the magnitude of the willingness of scientists and engineers working in $\mathrm{R} \& \mathrm{D}$ functions to accept a job in a non- $\mathrm{R} \& \mathrm{D}$ function conditional on $X$.

\section{Data}

The data used for our analysis was collected by means of an internet survey among Dutch Scientists and Engineers with a bachelor or master degree. All members of the Royal Institution of Engineers in the Netherlands (KIVI NIRIA) ${ }^{3}$ plus the subscribers of the weekly professional journal for scientists and engineers (Technisch Weekblad) were approached by e-mail to participate in the survey ${ }^{4}$ KIVI NIRIA members were approached by an e-mail from (the director of) KIVI NIRIA in which the aim of the survey was explained and a link to the survey was provided. Furthermore the survey was announced in the weekly newsletter and subscribers of Technisch Weekblad were approached by an e-mail on behalf of the editor. The survey was also announced in the journal. Our sample contains therefore those engineers and

\footnotetext{
${ }^{3}$ KIVI NIRIA is a professional organization that look after the interests of Dutch scientists and engineers and provide services that assist members with the development of their professional careers, for example individual advices on salary negotiations. Individual members get advice on (individual) salary negotiations.

${ }^{4}$ Since graduates from natural sciences disciplines at non-technical universities (mathematics, physics etc.) do not have the title Ingenieur (Ir) they are generally not members of Kivi Niria (although they may be subscribers of Technisch Weekblad) and will generally not be in the data. We do not think that this will be a problem as we may argue that preferences for $R \& D$ and non-R\&D functions are the same for mathematicians from technical and non-technical universities.
} 
scientists graduates who opted for a technical career and subsequently faced a choice between an R\&D jobs or a non-R \&D job.

As monetary incentives, 20 gift certificates of 50 euro were put on for raffle between the respondents and all respondents were told that upon completion of the questionnaire, they would be offered a free subscription to Technisch Weekblad and C2W, a professional journal about chemistry, life sciences and process technology. The response rate was about 20\%. About 6000 respondents started the interview. About one third of the respondents had not graduated yet or where already retired leaving about 4,396 individuals eligible for our study. After deleting individuals with missing values for the main variables of interest (job and wage) and selecting only those with a monthly wage larger than 1000 euros, working between 24 and 60 hours a week and aged under 66, 3,590 observations remained.

The survey included questions about the field of study, year of graduating, type of function, field of function, employer (number of employees, sector of industry) and earnings. Scientists and engineers in the Netherlands are employed in very different (technical) functions and only $18 \%$ are employed in an R\&D function. The probability of being employed in an R\&D job decreasing with age from about $25 \%$ at age 25 to about $10 \%$ at age 65 . Descriptive statistics of the main variables of interest are reported in Table 2.

We approach the worker's CWD by the willingness to pay for an R\&D job (WTP) and the willingness to accept an R\&D job (WTA). The WTA is the compensation a worker holding an $R \& D$ job demands for switching to a non-R\&D job. The WTP is the wage cut a worker holding an non-R\&D job is prepared to take to obtain an R\&D job. Theoretically we should have $C W D=W T A=W T P$ but it is known from the literature that in general $W T A>W T P$ (see Horowitz and McConell (2002). People demand a higher compensation for the loss of a good than the amount they are prepared to pay to obtain that good. Therefore the WTP is the lower limit for the CWD and the WTA the upper limit. To measure a worker's WTA and WTP, we followed the Contingent Valuation literature (see Hanemann (1994) for instance) and included the following two questions to the survey.

1. Individuals working in an $R \& D /$ non- $R \& D$ function were asked: 'At the moment you are working in a [field of function] function. Suppose you were offered [a non-R\&D function in the following field: (random selection of: construction/design, production, management, counseling, planning/coordination, quality control, education $] /[\mathrm{R} \& \mathrm{D}$ function] in the same region and under the same conditions (hours per week, nonpecuniary benefits) as your current function. What is the minimum 
salary that should be offered for you to accept the function?'

2. Furthermore we asked what wage sacrifice, i.e. willingness to pay, individuals were prepared to make in order to keep their offer: 'Imagine that your department or organization will be reorganized and part of the $R \& D$ positions/current position for non-R\&D functions will disappear. Employees in this position get the choice between a different function in the field of [random selection of: construction/design, production, management, counseling, planning/coordination, quality, control, education for R\&D function/ R\&D function for workers working in non-R\&D function] at their current salary or their current position at a lower salary. All other conditions remain the same for both functions. What is the lowest monthly gross earnings for which you should choose to work in your own function?'

Question 1 provides a measure of the WTA en question 2 a measure of the WTP. Taking the log of the answer to Question 1, ln $A n s_{1}$, and subtracting the $\log$ of the current wage gives us a measure of the WTA an R\&D job for those whose current job is R\&D, i.e. $\ln A n s_{1}-\ln w$. The WTA a non$\mathrm{R} \& \mathrm{D}$ job for those whose current job is non- $\mathrm{R} \& \mathrm{D}, \ln A n s_{1}-\ln w$. Assuming symmetry, that is assuming that the WTA an R\&D job for workers whose current job is non-R\&D were they employed in an $R \& D$ job is equal to - $\left(\ln w-\ln A n s_{1}\right)$, we define our measure of $W T A$ an R\&D job as:

$$
W T A=\left\{\begin{array}{lll}
\ln w-\ln A n s_{1} & \text { if } & R D=0 \\
\ln A n s_{1}-\ln w & \text { if } & R D=1
\end{array}\right.
$$

where $R D$ is a dummy that takes for value 1 if the worker's current job is $R \& D$ and 0 otherwise.

Similarly, taking the log of the answer to Question 2, $\ln A n s_{2}$, and subtracting this amount to the log of the current wage gives us a measure of the WTP to hold an R\&D job for those whose current job is R\&D, i.e. $\ln w-\ln A n s_{2}$ and the WTP to hold a non-R \&D job for those whose current job is non- $\mathrm{R} \& \mathrm{D}, \ln w-\ln A n s_{2}$. Assuming symmetry, that is assuming that the WTP to hold an R\&D job for workers whose current job is non-R \&D were they employed in an $\mathrm{R} \& \mathrm{D}$ job is equal to $-\left(\ln w-\ln A n s_{2}\right)$, we define our measure of $W T P$ an $R \& D$ job as:

$$
W T P=\left\{\begin{array}{lll}
\ln A n s_{2}-\ln w & \text { if } & R D=0 \\
\ln w-\ln A n s_{2} & \text { if } & R D=1
\end{array}\right.
$$


Unfortunately, from the 3,590 respondents for which complete information about their job, wage and demographics is available, roughly 740 did not answer question 1 or question 2. One reason for that may have been that the questions were at the end of the questionnaire 5 However, fortunately enough, the probability of not answering question 1 or 2 is not significantly related to observable characteristics like wage, hours work, function or fields of education and only appears to be larger for those with more experience. From the 2,850 that answered either question 1 or 2, roughly a fifth answered "I don't know". The probability of answering "I don't know" to question 1 or 2 is not significantly related to observable characteristics like wage, hours work, job type or fields of education and only appears to be larger for those with more experience and no permanent contract. After trimming for extreme values defined as more than twice or less than half the current wage, our sample contains complete information, including WTA and WTP, for 1,969 respondents. Note that the distribution of workers to types of jobs is preserved as 374 or $19 \%$ of those answering both questions have an R\&D job compared to 646 or $18 \%$ of the full sample.

Carson et al. (1996) have shown that when it is possible to compare CV measures with other measures using real transactions like hedonic prices, the results are often fairly close, with the CV measure being usually slightly lower than the revealed preference estimate but both being highly correlated with a range of correlations between 0.78 to 0.92 . Despite this empirical evidence, the main criticism about the use of WTA and WTP is that the question asked to elicit WTA/P may appear to be a silly one to the respondents or the respondent's answer to the question may just be the result of picking a number. These critics refer to the credibility and reliability of the question used to elicit WTA/P (see Diamond and Hausman (1994)). Credibility refers to the extent to which the respondents answer the question asked by the interviewer. Reliability refers to the size and direction of the bias in the respondent's answer ${ }^{6}$

\footnotetext{
${ }^{5}$ The last question of the survey was an open question about the respondents opinion about the questionnaire. Those that answered the question complained about the length of the questionnaire and especially the section on measuring competencies included in it and appearing right before question 1 and 2 above. However, none did complain about question 1 and 2 .

${ }^{6} \mathrm{~A}$ third point of concern is the precision of the measurement. This refers to the variability in the responses and is most relevant for small sample size surveys. Given the rather large size of our sample, the precision problem could be dismissed without further arguments.

An example of the incredibility of WTA/P measures often cited is summarized in the following question: How meaningful is the answer of randomly chosen persons in a shopping Mall about their willingness to pay for preserving the environment. As Hanemann
} 
The most important factor for the credibility of WTA/P lies in the way these values are elicited, i.e. credibility is embedded in the question itself. For WTA/P to be credible, the question should be specific and realistic to the persons interviewed. We argue that the two questions posed in the survey used for this study are both very specific and very realistic for the respondents since the questions refer to situations that the respondents have been confronted with in the course of their career. Graduating from a technical university, the scientists and engineers interviewed have entered the labor market and considered the type of jobs they would prefer. Doing research or not? has probably been the most important question they had to answer in their career. They also have been confronted with the market and had to choose between applying for jobs with higher potential earnings but no research or lower potential earnings but including room for doing research. Furthermore, engineers and scientists continue to be confronted with this question, like other employees, as they may still decide to switch jobs if the gap between their job and the market wage for R\&D increases (decreases).

Hanemann (1994) argues that closed-ended questions should be preferred to open-ended question. The main argument behind this choice is that people tend to have difficulties in putting a price behind their preferences. Suggesting a price and asking if they would accept or pay at that price and randomizing the amount proposed to the various respondent should overcome this issue. However, this argument holds for valuing the WTA/P of products for which prices are posted and hence people do not bargain. In our case, people were asked about their (virtual) wage (monthly or yearly). Since wages are not posted $]^{7}$ but bargained at the hiring moment, it seems reasonable to expect that open-ended and closed-ended questions would deliver merely the same answer. The main advantage of open question for our study is that they allow us to directly measure WTA and WTP instead of using the share of workers accepting an R\&D job.

(1994) argued, this way of eliciting WTA/P is of course not credible even for the strongest supports of the Contingent Valuation technique and does certainly not correspond to the methodology used by careful practitioners. Hanemann (1994) provided several directions to follow in order to increase the credibility of CV. For instance, the survey should follow the rules of probability sampling as opposed to convenient sampling in the shopping Mall or consists of in-person interview as opposed to self-administered surveys for they allow the interviewer to control the process. He also recognized that since in-person interviews are much more expensive, they would lead to an inevitable reduction of the sample size and hence in the precision of the measurement.

${ }^{7}$ Sometimes ranges of wages are posted on job offers but the actual wage still remains to be bargained about. 


\section{Empirical Results}

\subsection{Preliminary results}

First of all, we run a simple earnings regression. Corrected for observable characteristics, R\&D workers earn $3.5 \%$ less than non-R\&D workers (Table 3). Earnings regressions on the restricted and full samples show very similar results suggesting that the restricted sample is not very selective with respect to earnings and $R \& D$ preferences. As we will see below the wage penalty for doing R\&D greatly underestimates the CWD for R\&D.

We have also estimated the parameters of the wage regression using control function techniques. The technique consists of two steps. In the first step, we ran a regression of $R \& D$ on the set of explanatory variables included in the OLS wage regression above (without excluded variables since, as argued in section 2, there are no valid instruments in a single cross-section). We then used probit techniques and calculated the value of the control function for the linear fitted values. In the second step, we included the control function as an additional regressor in the OLS wage regression. Identification requires the control function to be nonlinear when no exclusion restrictions exist. In our data, although a quadratic fit of the control function is significantly better, the $R^{2}$ of the linear fit is equal to 0.90 indicating that the linear fit already explains $90 \%$ of the variance. More important, the $R^{2}$ of a regression of the control function on the other explanatory variables is about 0.93 indicating strong multicollinearity in the wage regression. Finally, the coefficient of the control function is equal to 0.08 and is not significant and the coefficient of $R \& D$ remains stable at $-3.5 \%$. These results cast some doubts on the identification of the model.

Now we turn to the WTA/WTP measures. Table 4 gives the WTA/WTP measures for R\&D and non-R\&D workers. For R\&D workers the mean WTA is $0.15 \mathrm{log}$ points. The WTA of non-R\&D workers ranges from $-0.05 \mathrm{log}$ points for workers employed in management functions to -0.09 for workers employed in communication functions. The mean WTP for R\&D workers is $0.11 \mathrm{log}$ points. As expected the mean WTP for R\&D workers is below the mean WTA but the difference is small. The WTP for non-R\&D workers ranges from $-0.06 \log$ points for workers employed in education to $-0.10 \log$ points for workers employed in management functions. We have randomized the type of job proposed to R\&D workers as their alternative job but interestingly

enough, we found no differences in the distribution of WTA and WTP by type of function except for the WTA in "Education" function included in the "other" function which is found to be lower than the WTA in all other functions (Table 5). 
The mean and median of the difference between our WTA and WTP measures are very close to 0 and the interquartile is around 25 percent points as indicated in Table 6. To summarize, our measures of WTP and WTA appear to be quite robust across functions and the WTP seem to be slightly more stable than the WTA.

\subsection{Main results}

Table 7 gives the results of the WTA/WTP regressions. The OLS estimates of the R\&D coefficient in the WTA equations shows that the minimum wages for which R\&D workers are willing to accept an R\&D job are $22 \%$ lower than that of non-R\&D workers. It is to be expected that the WTA increases with age, experience and tenure as older and more experienced workers with long tenure are more likely to have recognized a good job match and will therefore be more reluctant to switch jobs. Surprisingly this seems not to be the case. Other observable individual and job characteristics such as hours worked, gender and sector of industry do not impact on WTA and WTP either. The WTP estimate gives a relative preference parameter of 0.19 log points, showing that R\&D workers are prepared to pay $19 \%$ more than non-R\&D workers to continue working in an R\&D job. Except for the type of contract, observable individual and job characteristics do not have a significant impact on the WTP. Workers with a permanent contract are less prepared to pay for an R\&D job than workers with a temporary contract.

To see whether we can relate $R \& D$ preferences to other worker characteristics we included workers' valuations of job characteristics in the WTA/WTP regressions. Workers were asked to rate on a 5 point likert scale how much value they attached to certain job characteristics $(1=$ not at all important, ... $5=$ very important) such as work autonomy, salary, job certainty etc. It is found that the more value workers attach to work autonomy, a high salary and the possibility to combine work and family roles the lower the WTA for R\&D. Workers who think it is important to be able to learn new things at work have a higher WTA. Surprisingly, workers who attach much value to a high salary have a small but significant higher WTP. Finally we included a dummy variable for workers who were searching for another job at the time of the survey. Workers who were searching for another job have a lower WTA and a lower WTP. Although some of the job characteristics valuations and the job search dummy have a significant impact on the WTA/WTP they explain very little of the variance. 


\section{Robustness check}

Note that the assumption of symmetry between workers employed in R\&D and workers employed in non-R\&D functions may lead to overestimation of the preference effect if workers are reluctant to switch jobs for reasons that have nothing to do with the type of their current job. For example because job switching involves switching costs. Although the respondents were told that the alternative job was in the same region under the same non-pecuniary conditions we cannot completely rule out switching costs due to other reasons. Due to the symmetry assumption switching costs will work in different directions for $R \& D$ and non-R\&D workers in which case the $R \& D$ coefficient in the WTA/WTP regressions will be overestimated. Note however, that our WTA/WTP regressions control for age (experience), job tenure, permanent contract, variables also entering the switching costs function. Furthermore including the searching for a job dummy does not affect the coefficients for $\mathrm{R} \& \mathrm{D}$ when entered into the regression. This provides strong evidence against bias in our measures. Nevertheless we will also consider an alternative measure for WTA/WTP which does not depend on the symmetry assumption. This alternative measure combines both questions. The WTA for R\&D workers is given by the answer to question 2, while the WTA for non-R\&D workers is given by the answer to question 1 . Similarly the answer to question 1 provides a measure of the WTP for R\&D workers and the answer to question 2 a measure of the WTP of non-R\&D workers.

$$
\begin{aligned}
& W T A=\left\{\begin{array}{lll}
\ln w-\ln A n s_{1} & \text { if } & R D=0 \\
\ln w-\ln A n s_{2} & \text { if } & R D=1
\end{array}\right. \\
& W T P=\left\{\begin{array}{lll}
\ln w-\ln A n s_{2} & \text { if } & R D=0 \\
\ln w-\ln A n s_{1} & \text { if } & R D=1
\end{array}\right.
\end{aligned}
$$

An advantage of this measure of the WTP/WTA is that possible switching costs, provided that they have the same size for $R \& D$ and non-R\&D workers, are canceled out in the WTA/WTP regressions, because they work in the same direction for $R \& D$ and non-R\&D workers. A disadvantage of mixing the two questions is that the answers will typically depend on the exact phrasing of the question. Part of the difference between R\&D and non-R\&D workers found by using this measure may be a result of using different questions for both groups. However, it was found that the mean difference between WTA and WTP measures when using the same questions for both groups was close to zero, suggesting that

$$
\left|\ln w-\ln A n s_{1}\right| \approx\left|\ln w-\ln A n s_{2}\right|
$$


So it is to be expected that the effect of mixing two questions to measure WTA/WTP will be negligible.

Table 8 gives the results of the OLS regressions with the alternative measures of WTA/WTP. Again the R\&D preference parameter is considerable, ranging from $0.18 \mathrm{log}$ point for the WTA to $0.23 \mathrm{log}$ point for the WTP. These results show that the estimated preference effect is quite robust for the WTA/WTP measures chosen.

\section{Conclusion}

In this paper we show that traditional measures of $R \& D$ compensating wage differentials by earnings regressions are severely biased downwards. In equilibrium workers are sorted into jobs on both worker and job characteristics. For that reason there exists no valid instrument in a single cross section for either job characteristics or worker characteristics. Identification in control function models therefore hinges on the nonlinearity of the control function. In our data, a linear fit of the control function explains $90 \%$ of the variation and more important, the control function appears to be extremely correlated with the explanatory variables included in the wage regression. To circumvent the sorting issue we propose direct measures of the willingness to pay and the willing to accept an R\&D function. We asked R\&D (non-R\&D) workers for what salary they would be prepared to switch to non-R\&D (R\&D) jobs and what salary they were prepared to accept in order to keep their current job. Using these direct measures of the willingness to accept and the willingness to pay for an $R \& D$ job we show that the relative wage reduction accepted by the average R\&D worker ranges from $19 \%$ to $22 \%$. The policy implication of these findings is that wage policies will be very inefficient in increasing the number of $R \& D$ workers. Relatively low wages in $R \& D$ do not hinder the retention of $R \& D$ workers as for this group low wages are compensated by other aspects of R\&D work. However, to persuade non-R\&D workers to switch to R\&D jobs, wages in R\&D should increase enormously.

A more promising line would be to influence workers' preferences for $R \& D$ jobs. However, the differences between $R \& D$ and non-R\&D workers cannot be explained by any observable job or individual characteristics such as age, experience, tenure or sector of industry. We also tested whether observable preferences such as a preference for work autonomy, salary, job certainty and interesting work have any impact on the WTA and WTP measures. Although observable preferences do indeed have some impact on WTA and WTP, this impact is relatively small and cannot explain the differences between $R \& D$ and non-R\&D workers. To influence workers preferences we need a better 
understanding of the factors that influence preferences for R\&D and nonR\&D jobs. That remains an issue for further research.

\section{References}

BARTiK, T. J. (1987): "Estimating Hedonic Demand Parameters with Single Market Data: The Problems Caused by Unobserved Tastes," The Review of Economics and Statistics, 69(1), 178-80.

Brown, C. (1980): "Equalizing Differences in the Labor Market," Quarterly Journal of Economics, 94(1), 113-134.

Carson, R. T., N. E. Flores, K. M. Martin, and J. L. Wright (1996): "Contingent Valuation and Revealed Preference Methodologies: Comparing the Estimates for Quasi-Public Goods," Land Economics, $72(1), 80-99$.

Diamond, P. A., and J. A. Hausman (1994): "Contingent Valuation: Is Some Number Better Than No Number?," Journal of Economic Perspectives, 8(4), 45-64.

Epple, D. (1987): "Hedonic Prices and Implicit Markets: Estimating Demand and Supply Functions for Differentiated Products," Journal of Political Economy, 95(1), 59-80.

Hanemann, M. W. (1994): "Valuing the Environment Through Contingent Valuation," Journal of Economic Perspectives, 8(4), 19-43.

Horowitz, J. K., And K. E. MCConell (2002): "A Review of WTA/WTP Studies," Journal of Environmental Economics and Management, 44, 426-447.

Kahn, S., and K. LANG (1988): "Efficient Estimation of Structural Hedonic Systems," International Economic Review, 29(1), 157-66.

Krueger, A. B., And D. A. SchKade (2007): "Sorting in the Labor Market: Do Gregarious Workers Flock to Interactive Jobs?," IZA Discussion Papers 2730, Institute for the Study of Labor (IZA).

Lassibille, G. (2001): "Earnings distribution among Spanish engineers: research vs. non-research occupations," Research Policy, 30(4), 673-680.

MAREY, P. (2002): "Crowding out in the Dutch labour market for R\&D workers," ROA Report series. 
Rosen, S. (1974): "Hedonic Prices and Implicit Markets: Product Differentiation in Pure Competition," Journal of Political Economy, 82, 34-55.

Stern, S. (2004): "Do Scientists Pay to Be Scientists?," Management Science, 50, 835-853. 


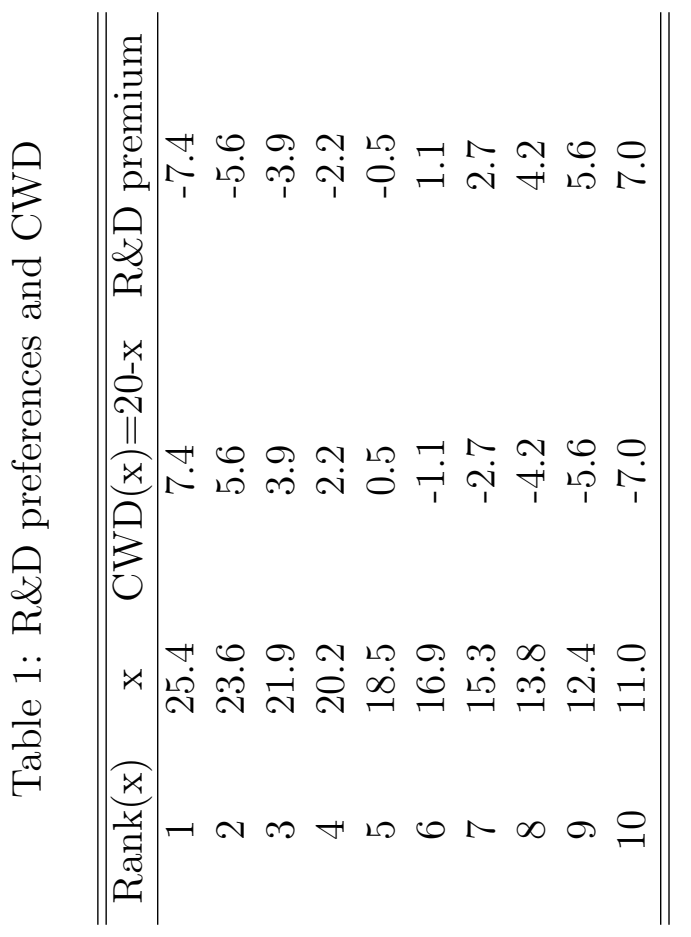




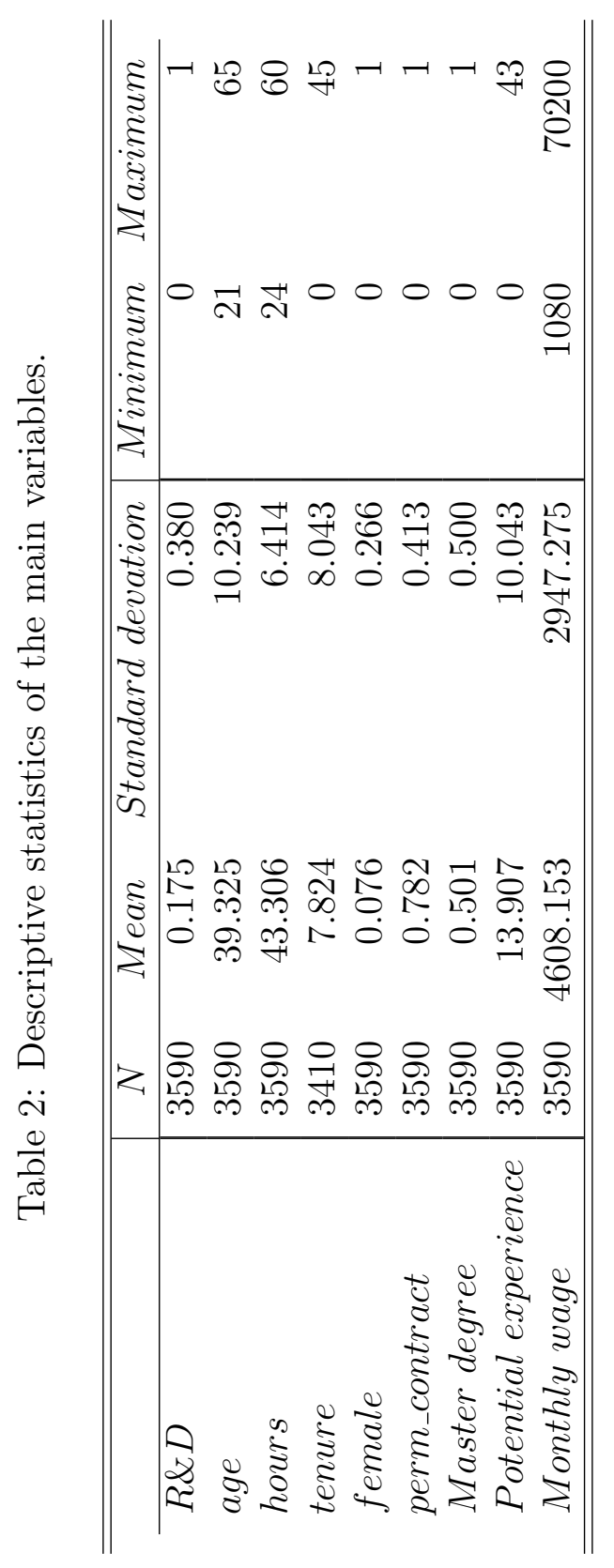




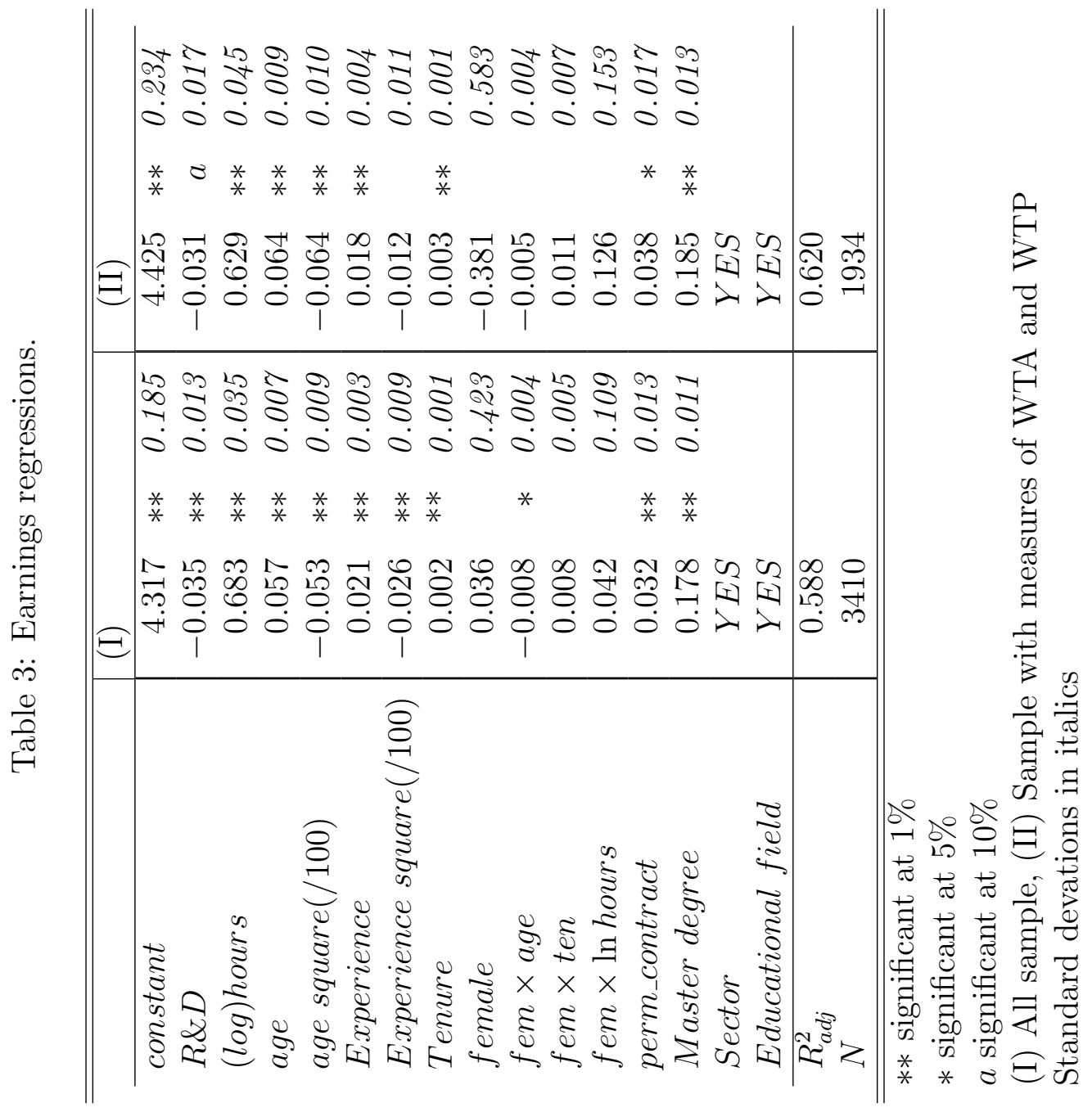




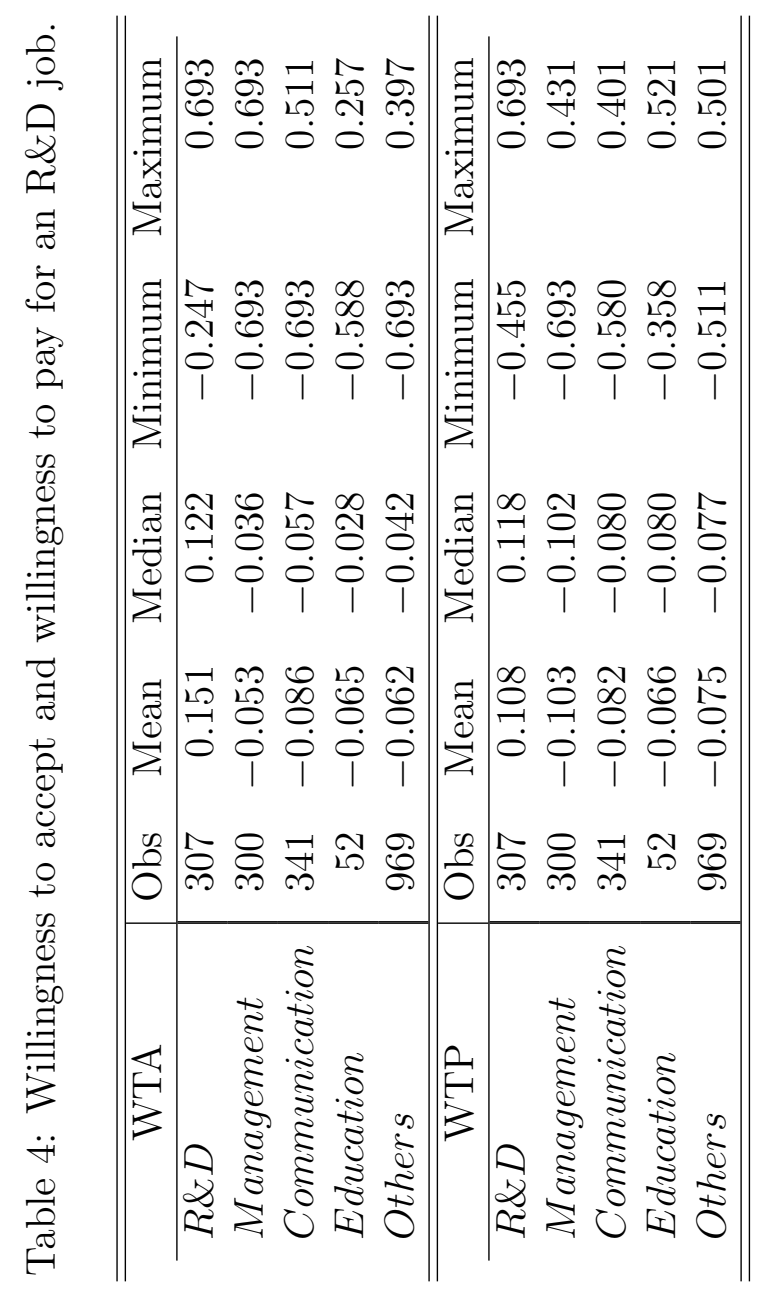




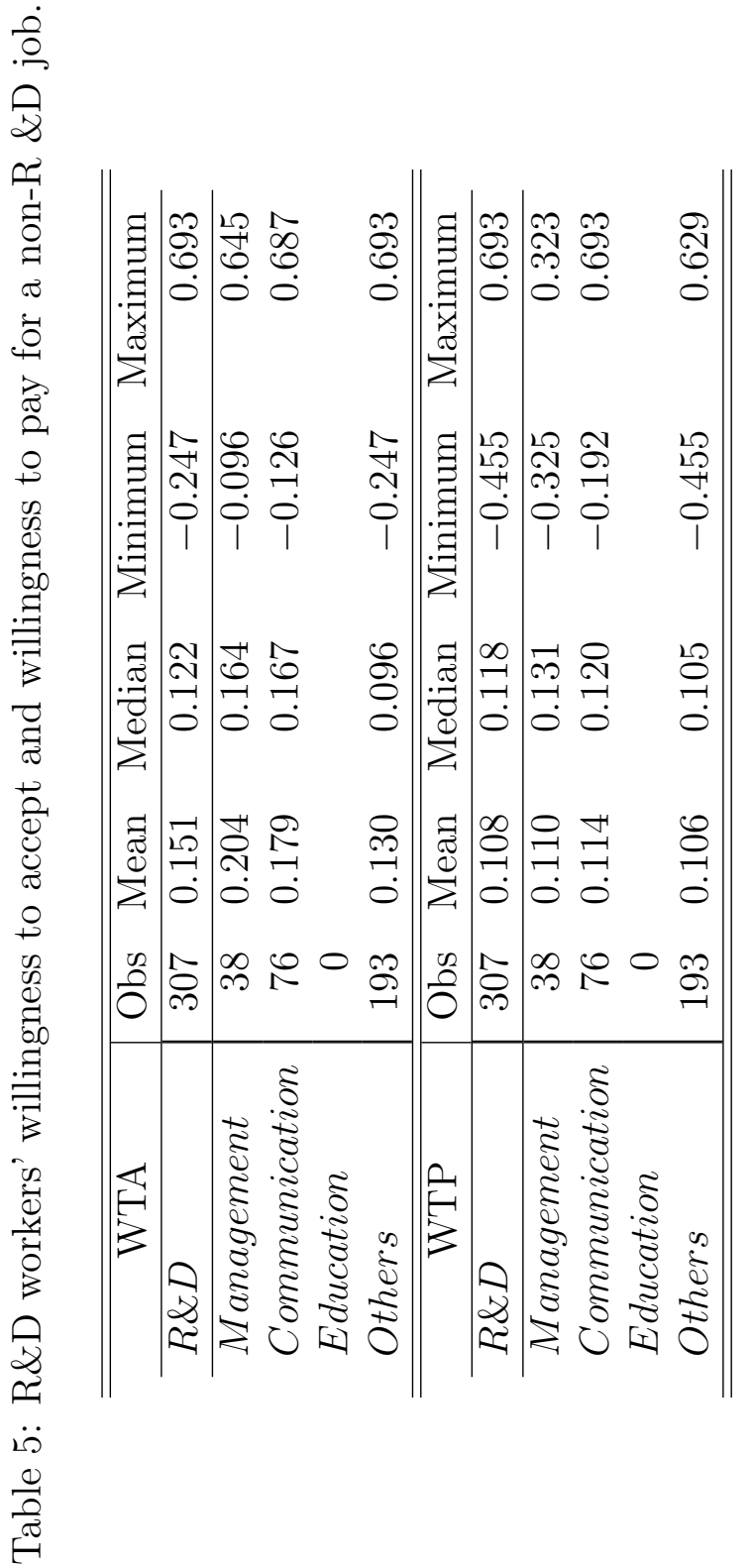




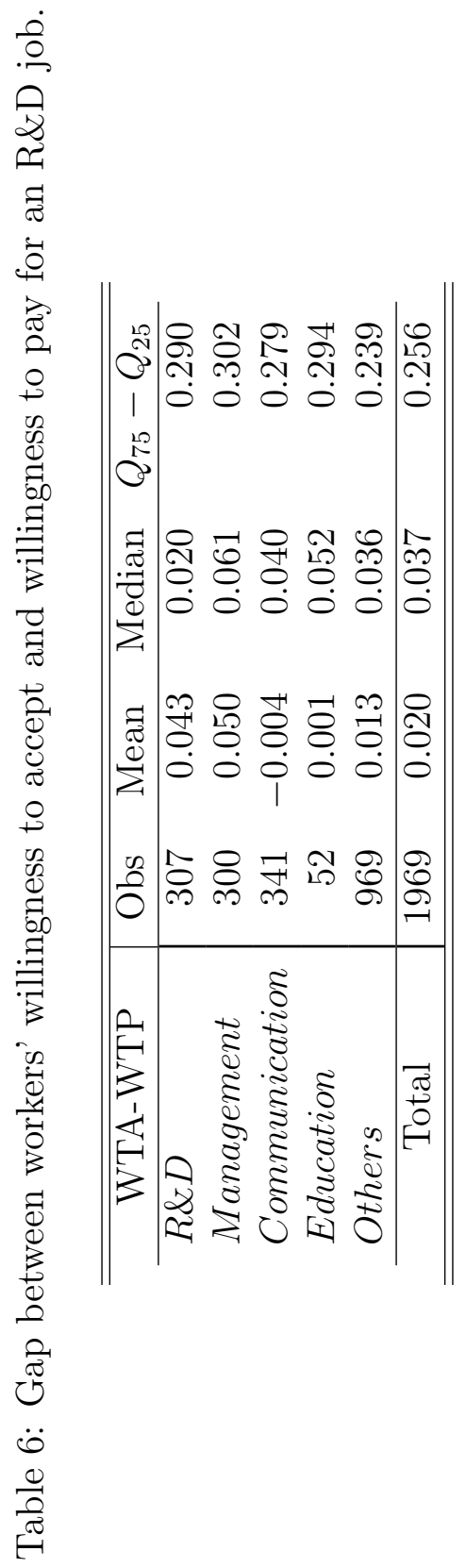




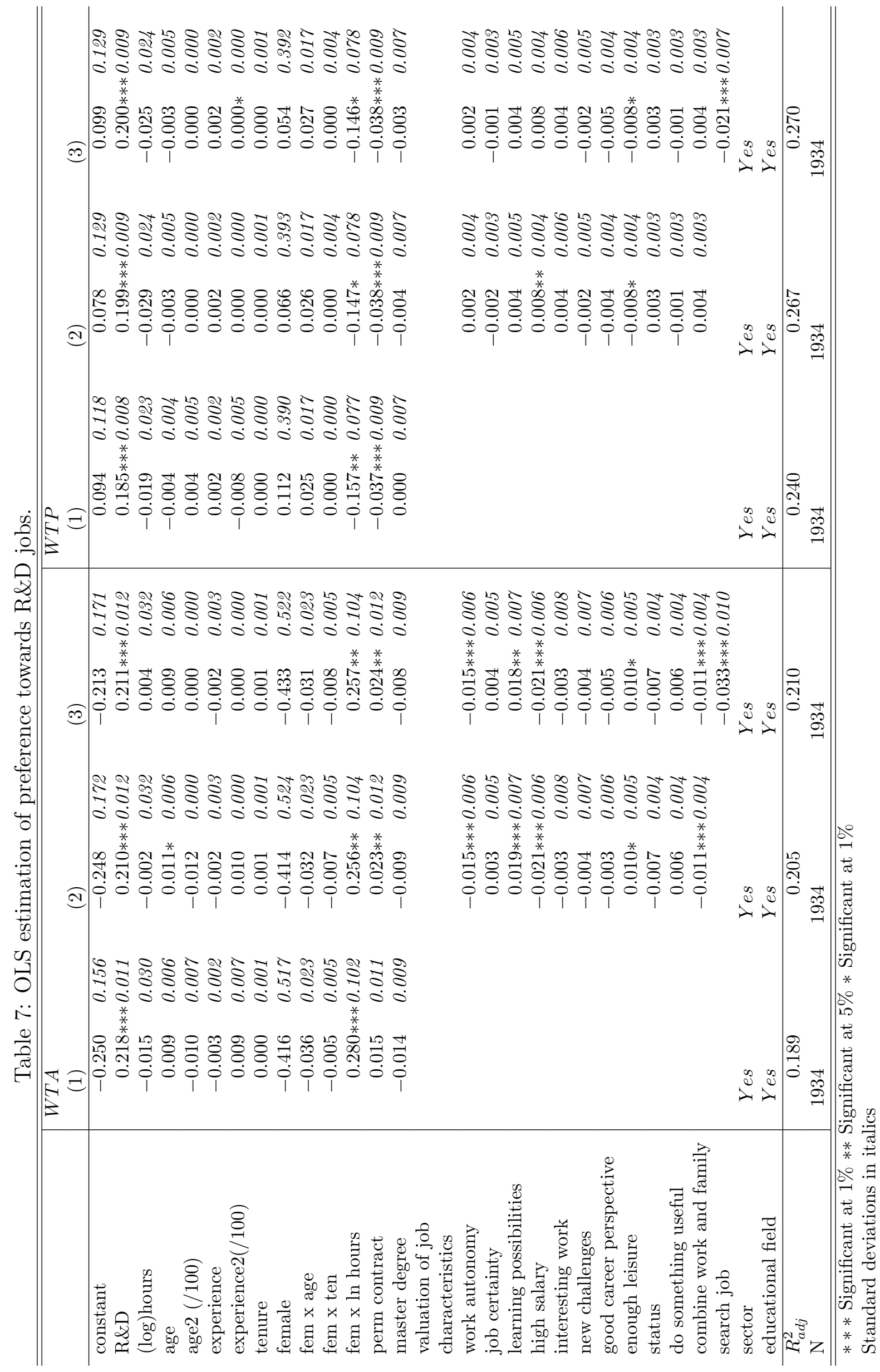




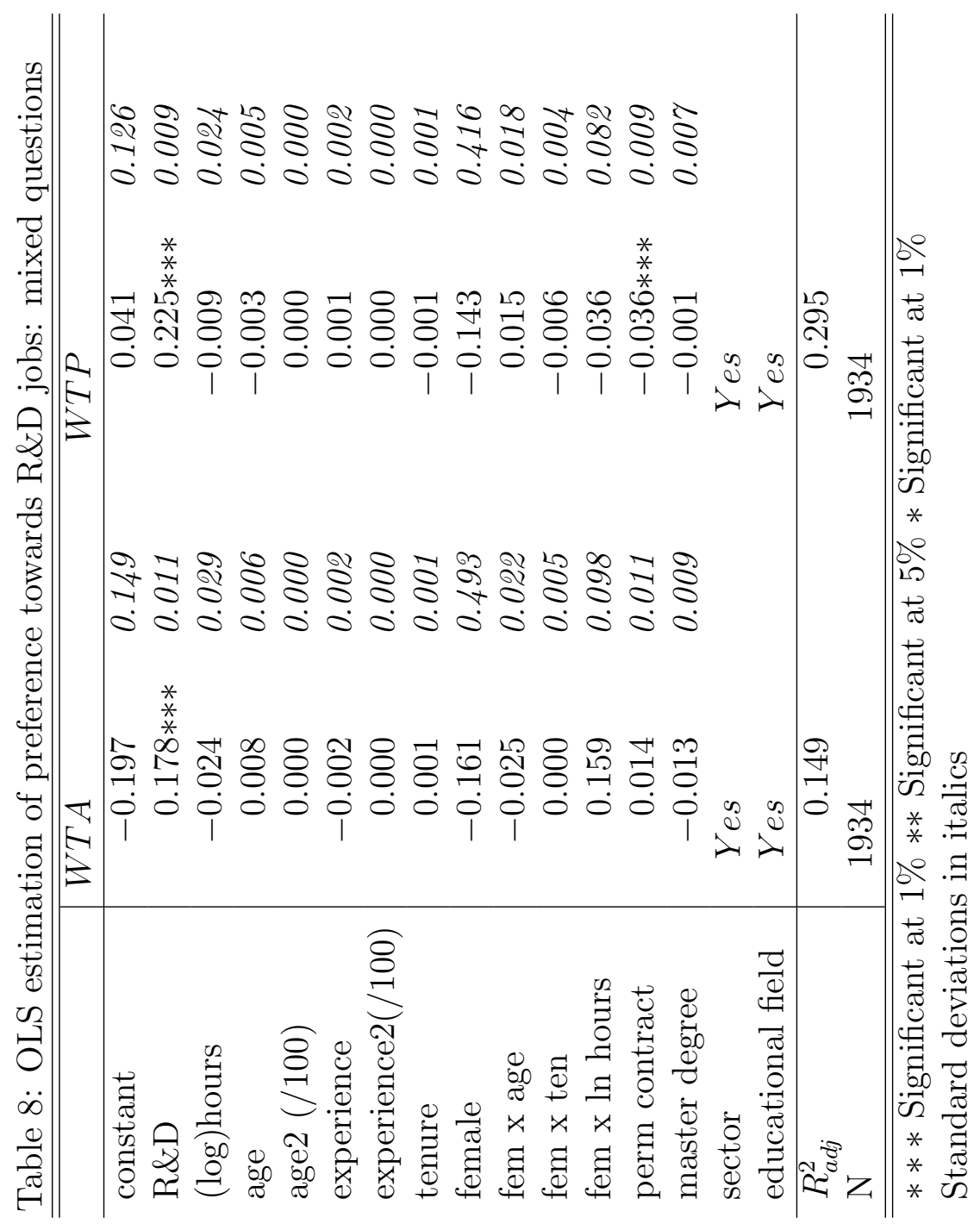

